\title{
Cuidados com a saúde da criança e validação de uma tecnologia educativa para famílias ribeirinhas
}

\author{
Care with the child's health end validation of an educational technology for riverside families \\ Cuidados con la salud de los niños y validación de una tecnología educativa para las \\ familias que viven cerca del rio
}

\begin{abstract}
Elizabeth Teixeira', Aldo de Almeida Siqueira", Joselice Pereira da Silva'", Lília Cunha Lavor"I
' Universidade Estadual do Pará, Curso de Graduação em Enfermagem, Grupo de Pesquisa Práticas Educativas em Saúde e Cuidado na Amazônia (PESCA). Belém-PA, Brasil.

" Universidade Estadual do Pará, Curso de Graduação em Educação Física (Bolsista PIBIC 2008). Belém-PA, Brasil.

II' Universidade Estadual do Pará, Curso de Graduação em Enfermagem (Bolsista PIBIC 2008). Belém-PA, Brasil.
\end{abstract}

Submissão: 25-10-2010 Aprovação: 23-01-2012

\section{RESUMO}

O estudo teve como objetivo conhecer os saberes e modos de cuidar da saúde da criança de 0 a 5 anos entre famílias ribeirinhas (Fase 1) e validar uma tecnologia educativa (Fase 2). Trata-se de uma pesquisa qualitativa descritiva. Com as mães, realizaram-se grupos focais e analise de conteúdo; com juízes-especialistas e público-alvo aplicaram-se formulários. O estudo revelou que a preocupação com os cuidados com a criança entre as famílias ribeirinhas perpassa as adversidades diárias, havendo dedicação e empenho dessas famílias em manter a saúde de suas crianças. A escuta sensível das mães apontou a necessidade de uma maior aproximação entre os profissionais de enfermagem e a família. A validação da tecnologia educativa foi convergente, dentro dos parâmetros considerados adequados.

Descritores: Enfermagem; Educação em saúde; Tecnologia educacional.

\section{ABSTRACT}

This study aimed to assess the knowledge and ways of caring for the child health 0-5 years between riverine (Phase 1), and to validate an educational technology (Phase 2). It was carried out a descriptive qualitative study. With the mothers, focus groups and content analysis were used, and with judges-specialists and target-public-applied, forms. The study revealed that the concern with the care of a child between the riverine families permeates the adversity daily, with dedication and commitment of these families in maintaining the health of their children. The sensitivity listening of mothers indicated the need for a closer relationship between nursing professionals and family. The validation of the educational technology was convergent, within the parameters considered adequate.

Key words: Nursing; Health education; Education technology.

\section{RESUMEN}

El estudio tuvo como objetivo evaluar los conocimientos y formas de cuidado de la salud de los niños entre 0-5 años entre familias ribereñas (Fase 1), y validar una tecnología de educación (Fase 2). Una pesquisa cualitativa y descriptiva fue realizada. Con las madres, fue usado los grupos de discusión y análisis de contenido; con los jueces y familias, se aplico un formulario. El estudio reveló que la preocupación con el cuidado de los niños entre los ribereños es marcada por las dificultades diarias; las familias tienen dedicación y compromiso en el mantenimiento de la salud de sus hijos. La escucha sensible de las madres indicó la necesidad de una relación más estrecha entre los profesionales de enfermería y la familia. La validación de la tecnología educativa convergió, dentro de consideraciones adecuadas.

Palabras clave: Enfermería; Educación en salud; Tecnología educacional. 


\section{INTRODUÇÃO}

Os saberes familiares necessários para cuidar da saúde da criança de 0 a 5 anos surgem a partir da necessidade de se resolver problemas diários, principalmente em comunidades isoladas, nos quais se incluem cuidados com a higiene, amamentação, alimentação, prevenção de patologias comuns na infância; quando dão certo são repassados como verdades, de geração a geração, uma espécie de tradição. Compreendendo esses conhecimentos como recursos utilizados pelas famílias e por terapeutas populares (benzedeiras e curandeiros), a aquisição dos saberes se constrói no cotidiano e não estão ligados, necessariamente, a serviços formais de saúde ${ }^{(1)}$.

Os caboclos ribeirinhos da Amazônia são populações tradicionais, às vezes isoladas, de transição entre os habitantes primitivos e os atuais. Seu modo de agir, ser e viver é peculiar, o que os diferencia dos demais, mas são ainda discriminados e segregados pela "sociedade urbana"; fizeram suas histórias às margens dos rios e florestas, conhecem os rios como ninguém e deles sobrevivem; os rios fazem parte de sua vida e dificilmente deles se separam. Entre os caboclos ribeirinhos e a natureza se estabelece uma relação de vida, árdua, difícil, de domínio e adaptação(2).

Cerca de 100 mil crianças ainda morrem anualmente no Brasil, e grande parte por causas evitáveis. No país a forma de cuidar das crianças na família sempre foi permeada de incertezas. No que se refere a população ribeirinha, devido à distância dos serviços formais de saúde, as famílias acabam desenvolvendo uma forma peculiar de cuidar de seus filhos(3).

Os estudos em enfermagem sobre saúde da criança de 0 a 5 anos tem se voltado sobremaneira ao acompanhamento do crescimento e desenvolvimento, que faz parte da avaliação integral à saúde da criança ${ }^{(4)}$. A consulta de enfermagem é destacada como um dos dispositivos do cuidado de enfermagem para este acompanhamento ${ }^{(5)}$. A ênfase dada nestes estudos, no entanto, é para as crianças que vivem em zonas urbanas e que estão inscritas em programas de crescimento e desenvolvimento de unidades e centros de saúde.

Um problema que se tornou significativo, e que tem grande destaque na literatura, interferindo no crescimento e desenvolvimento da criança e no convívio familiar é o acidente doméstico, sendo necessário que se reconheçam os fatores de risco e aspectos preventivos e promover ações educativas ${ }^{(6)}$. É nesse contexto que encontramos indicativos mais incisivos a favor de ações educativas.

As ações educativas que emergem no contexto da saúde da criança são concebidas como estratégia transversal, presentes na consulta de enfermagem a criança, podendo ser ampliadas a outras oportunidades educativas, como as oficinas educativas. Estas, podem despertar uma nova consciência para o cuidado com a criança, como se constatou em estudo sobre a saúde da criança desnutrida ${ }^{(7)}$. Neste estudo recomendam-se intervenções de educação permanente em saúde para grupos culturalmente distintos com vistas a buscar mudanças na constituição de novas práticas cuidativas ${ }^{(7)}$.

A educação em saúde é também uma estratégia transversal nas políticas de atenção a criança menor de 5 anos, pois promove a prevenção e promoção da saúde requerendo do profissional de enfermagem habilidade para desenvolver tecnologias e abordagens pedagógicas de educar para cuidar ${ }^{(8)}$. No contexto da educação em saúde é que se inserem as tecnologias educativas enquanto dispositivos para mediar processos de educação em saúde.

A enfermagem desempenha um papel importante na saúde e na doença, porque atua em diferentes níveis de prevenção e em diferentes contextos. Suas ações preventivas não devem ser estáticas ou isoladas, mas devem formar um elo contínuo na história natural de qualquer distúrbio ${ }^{(9)}$. Em virtude disso, é importante reconhecer e valorizar os saberes imbricados na vida dessas pessoas e suas implicações para as ações de enfermagem no que tange ao cuidar-educando da criança de 0 a 5 anos com vistas à produção de tecnologias educativas adequadas a cada realidade.

A análise das percepções e conhecimentos das mães sobre aspectos relacionados à saúde da criança, como a higiene, revela a influência de fatores socioeconômicos e culturais no modo de cuidar dos filhos, e esse conhecimento, contextualizado na realidade das famílias, possibilita um planejamento para as atividades de enfermagem no que tange ao cuidar-educando ${ }^{(10)}$.

Em estudo sobre o conhecimento da família acerca da saúde da criança sobre a condição crônica na infância, constatou-se que as informações às famílias têm ocorrido de forma sutil gerando dificuldades em apreendê-las por conter um vocabulário muito técnico e específico, impossibilitando o desenvolvimento da autonomia no cuidado com a criança, o que indica a necessidade de adoção de novas e outras estratégias de informação para o cuidar-educando ${ }^{(11)}$.

Em estudo com famílias ribeirinhas na região Sudeste, concluiu-se que os familiares necessitam de orientações sobre os problemas de saúde das crianças por parte dos profissionais de saúde e torna-se relevante a participação do (a) enfermeiro (a) nesse sentido com vistas à promoção da saúde da população infantil[(12).

Durante o Curso de Graduação em Enfermagem em uma universidade na região Norte, o acesso à realidade e cultura das comunidades ribeirinhas, se deu de forma esporádica, pois nossos estágios estavam voltados para a assistência à população da zona urbana, que tem acesso a todos os programas desenvolvidos pelo Ministério da Saúde.

Essas considerações justificam o nosso interesse em desenvolver uma pesquisa sobre a saúde da criança ribeirinha na região, com vistas à produção e validação de uma tecnologia educativa para as famílias. Acreditando na contribuição do estudo e fomentados pelo desejo de conhecer o sincretismo histórico-cultural que permeia a vida dos ribeirinhos, transpusemos os muros da universidade para investigar os saberes e os cuidados da família para com a saúde das crianças de 0 a 5 anos. Partimos do pressuposto que tais saberes estão inter-relacionados com vários aspectos da vida dessas pessoas. Fatores culturais, socioeconômicos, ambientais, religiosos, interferem e fazem parte da construção desses saberes.

Assim, esse estudo tratou de conhecer os saberes e os modos de cuidar das famílias para com a criança ribeirinha de 0 a 5 
anos. A partir desse contexto, propusemos as seguintes questões norteadoras: a) Como as famílias ribeirinhas cuidam das crianças de 0 a 5 anos? b) Quais os saberes que estão envolvidos no cuidar das crianças de 0 a 5 anos? c) Como os fatores socioeconômicos, religiosos, ambientais e culturais das tradições herdadas ao longo das gerações manifestam-se na forma de cuidar das famílias com as crianças de 0 a 5 anos? d) Que aspectos são destacados por juízes-especialistas e público-alvo sobre uma tecnologia educativa elaborada com base nesses saberes?

O objetivo geral o de foi conhecer os saberes e modos de cuidar das famílias ribeirinhas relacionados à saúde da criança de 0 a 5 anos e validar uma tecnologia educacional. Os específicos: Descrever as formas de cuidar das famílias para com a criança de 0 a 5 anos; Investigar os saberes que estão envolvidos no cuidar da criança de 0 a 5 anos; Analisar de que forma os fatores socioeconômicos, ambientais, religiosos e culturais das tradições herdadas ao longo das gerações manifestam-se na forma de cuidar das famílias com a criança de 0 a 5 anos; identificar que aspectos são destacados por juízes-especialistas e público-alvo sobre uma tecnologia educativa elaborada com base nesses saberes.

\section{METODOLOGIA}

Para o alcance dos objetivos propostos o estudo adotou uma abordagem qualitativa descritiva (Fase 1) e quanti-qualitativa do tipo pesquisa metodológica(13) (Fase 2). Buscamos conhecer as singularidades e como estas interferem no conhecimento do todo. Parece impossível conhecer as partes enquanto partes sem conhecer o todo, menos possível ainda conhecer o todo sem conhecer singularmente as partes; a complexidade encontra-se justamente no âmago da relação entre o simples e o complexo porque uma relação é ao mesmo tempo antagônica e complementar ${ }^{(14)}$.

A escolha do local para a pesquisa (Comunidade do Tauari) aconteceu a partir do trabalho voluntário desenvolvido pelas autoras no Projeto Saúde e Alegria em que, por meio do envolvimento com a realidade dessa comunidade ribeirinha, pôde-se perceber a necessidade de um levantamento de dados acerca do modo de cuidar das famílias em relação às crianças de 0 a 5 anos. Para a pesquisa (Fase 1), realizamos seis visitas à comunidade, e pudemos acompanhar melhor e perceber mais intensamente a realidade. As visitas à comunidade ocorreram em ocasiões e de formas distintas: a) durante as expedições do Barco Abaré (Projeto Saúde e Alegria) que presta atendimento médico, de enfermagem e odontológico, implementando os programas do Ministério da Saúde e desenvolvendo arte e educação na comunidade; b) de ônibus; c) em um carro fornecido pelo projeto Saúde e Alegria. A produção dos dados ocorreu nos domicílios escolhidos pelos moradores para nos reunirmos. A comunidade de Tauari está situada no coração da Amazônia Legal, na Floresta Nacional do Tapajós (FLONA) às margens do lago de Tauari, no Rio Tapajós

A assistência de saúde está ancorada no atendimento do Barco Hospital ABARÉ, que faz expedições para FLONA a cada 40 dias realizando consultas médicas, de enfermagem e odontológicas, atividades de arte e educação em saúde. Nos períodos de ausência do ABARE, não há visitas de médicos ou enfermeiros, somente um agente comunitário fica responsável por marcar as consultas para a expedição seguinte.

O local da validação da tecnologia educativa (Fase 2) foi o município de Santarém no que tange aos juízes-especialistas e a mesma localidade (Tauari) no que tange ao público alvo.

Os sujeitos da Fase 1 foram 15 indivíduos (homens e muIheres), selecionados após atenderem alguns critérios: serem pertencentes à famílias que possuíam crianças de 0 a 5 anos, maiores de 18 anos e que residissem na comunidade há pelo menos 5 anos. A coleta de dados só ocorreu depois que os participantes se dispuseram a participar da pesquisa após esclarecimento verbal e por escrito através do Termo de Consentimento Livre e Esclarecido. A identificação dos moradores se deu a partir dos registros encontrados nos arquivos do projeto. O término da coleta de dados se deu quando se atingiu o ponto de saturação. Para garantir o anonimato, utilizamos nomes de rios e igarapés da região, que são de origem indígena.

Os sujeitos da Fase 2 foram 5 juízes-especialistas (identificados como especialistas em saúde da criança, docentes da Universidade do Estado do Pará e assistentes do Hospital Municipal, residentes no município de Santarém-PA) e 13 mães representando o público alvo (identificadas a partir da etapa 1 do estudo, residentes em Tauari-PA). Para garantir o anonimato, os sujeitos dessa fase foram identificados por códigos alfa-numéricos. Todos assinaram um Termo de Consentimento Livre e Esclarecido.

$\mathrm{Na}$ Fase 1, foram realizados grupos focais (com 6 a 10 participantes), com integrantes das famílias para coletar as informações. Esta técnica foi a mais indicada para a pesquisa porque permitiu que os participantes expressassem livremente suas opiniões, fizessem perguntas e, ao longo da produção de dados, abriu-se espaço para a realimentação entre os pesquisadores e os entrevistados, e novos questionamentos e esclarecimentos sobre o cuidar da criança puderam ser feitos. As discussões foram gravadas o que permitiu manter a fidedignidade do conteúdo emitido oralmente pelos participantes. Houve a interrupção da produção de dados quando se atingiu o ponto de saturação (momento em que não se apresentaram mais novas informações nas discussões).

No desenvolvimento dos grupos focais foi utilizado um roteiro com dois eixos norteadores. Na medida em que a conversa em grupo se desenvolvia, íamos estimulando os integrantes com questões sobre os itens de cada eixo, para dar sentido e amplitude à discussão: eixo 1 - perfil da comunidade; eixo 2 as famílias e o cuidar das crianças de 0 a 5 anos. $O$ eixo 2 foi desdobrado nos seguintes aspectos: a) A Família: Perfil sócio-cultural e econômico: religião praticada, manifestações culturais de que participam, trabalhadores na família, renda e lazer; a casa onde moram: estrutura e saneamento; b) As Crianças de 0 a 5 anos: o dia-a-dia das crianças, água e alimentação das crianças, amamentação e vacinas, atividades lúdicas e brincadeiras, práticas populares e tradicionais quando as crianças de 0 a 5 anos adoecem (plantas, rezas, amuletos etc.), itinerário terapêutico da família no trato da saúde e da doença das crianças.

Na Fase 2, aplicamos formulários aos juízes-especialistas e público alvo: após a assinatura do TCLE, cada juiz-especialista 
recebeu uma cópia do Caderno "Criança Saudável" e o formulário de avaliação com as instruções de preenchimento. Determinamos um prazo de entrega dos documentos de acordo com a disponibilidade do juiz-especialista.

Para aplicarmos os formulários com o público alvo, realizamos uma viagem à comunidade Tauari (o campo da pesquisa). Após o consentimento do presidente da comunidade, escoIhemos 13 famílias que tinham crianças de 0 a 5 anos. A cada família, representada por um membro (mãe), foi apresentado o Caderno e seus objetivos; na ocasião o respondente assinou o TCLE, e então foi aplicado o formulário. Os pesquisadores fizeram as perguntas relativas à avaliação e preencheram o instrumento de acordo com as respostas dos informantes.

A análise dos dados da Fase 1 foi realizada levando-se em consideração os objetivos, as questões norteadoras propostas e o referencial teórico. A técnica de análise foi a análise temática por meio da identificação de eixos temáticos considerados relevantes, escolhidos conforme frequência de aparecimento nos relatos gravados dos entrevistados. A análise dos dados da Fase 2 foi realizada de forma quantitativa ${ }^{(10)}$.

O trabalho foi submetido à avaliação do Comitê de Ética em Pesquisa (CEP) na Universidade do Estado do Pará, Campus XII - Santarém. Foi aprovado em 10 de setembro de 2008 (Protocolo 031/2008).

\section{CUIDADOS COM A SAÚDE DA CRIANÇA E IMPLICAÇÕES PARA O CUIDAR-EDUCANDO}

A pesquisa de campo (Fase 1) revelou a complexidade do cuidar cotidiano de saúde. Neste artigo destacamos algumas dimensões, as mais significativas para a produção da tecnologia educativa validada. Das respostas emergiram as questões-chave contempladas no Caderno "Criança Saudável".

Verificamos que Tauari não possui um sistema de educação infantil para as crianças menores de 5 anos, em geral as mesmas vão para a escola somente na primeira série do ensino fundamental. De acordo com os pais o dia a dia das crianças resume-se a brincadeiras.

"Ele só faz brincar e dormir... e comer também. Ele brinca aí dentro de casa mesmo, com uma bolinha. Eu não deixo ele brincar muito aqui fora porque tem muita formiga e o sol é quente pra ele."(Suruaca).

"Ele ainda é pequeno, então ele acorda e passa o dia brincando." (Maguari).

Quanto a esse aspecto, iniciamos a Cartilha com reflexões sobre a brincadeira, o brincar e os brinquedos, dando ênfase a alguns materiais que podem servir para a produção de brinquedos, como a palha e as garrafas PET. A brincadeira é considerada um aspecto construtivo para o desenvolvimento da criança, e através das brincadeiras a criança pode explorar a sua criatividade, preparando-se para as próximas etapas de sua vida(15). A saúde mental, na família em geral, e entre as crianças em particular, emerge de inúmeros determinantes do dia a dia, o que indica a relevância para o cuidar-educando da criança de 0 a 5 anos de estarmos atentos para aspectos como o lazer e o brincar.

Patologias comuns na infância estão relacionadas ao cuidado com a água contaminada ou ao uso sem tratamento adequado, resultando em doenças diarréicas e verminoses prevalentes nesta idade. As doenças de origem hídrica são aquelas em que a água serve como meio de transporte para os germes patogênicos atingirem o homem(16). Os cuidados com a água são destaque entre as famílias.

"Sei que é muito importante ter cuidado com a água que a gente dá pra eles! Eles são pequenos qualquer coisa fica logo doente [...]" (Paraíso).

Com a instalação do micro-sistema de água na comunidade de Tauari, as famílias deixaram de utilizar água do rio para beber e preparar alimentos, ficando esta água fluvial restrita somente a banhos e lavagem de roupas. A água chega encanada até as casas; as famílias que não recebem a água encanada utilizam água do poço. $\mathrm{O}$ agente comunitário de saúde distribui o hipoclorito de sódio que é utilizado para tratar a água, porém há uma resistência dos moradores no tratamento da água, como mostram as falas a seguir:

"Esse cloro muda muito o gosto da água, ela fica com um gosto ruim, eu coloco só dois pingos e já fica ruim; eles também não gostam de beber água com cloro e muitas vezes também não tem esse cloro, ai eu dou pra eles assim mesmo [...]" (Paraíso).

Nesse sentido, na Cartilha reforçamos a importância do hipoclorito e destacamos as doenças de veiculação hídrica; as populações ribeirinhas têm uma relação intensa com a água; os rios além de serem as ruas para essas famílias são espaços de lazer, banho, lavagem de roupa etc., o que precisa ser sempre reforçado no cuidar-educando nesses contextos.

No que se refere ao cuidado com a alimentação, constatamos que a composição alimentar das famílias de Tauari é fortemente baseada em carboidratos, provenientes da farinha de mandioca e seus derivados; e em proteínas provenientes dos peixes; a ingestão de vitaminas, fibras e sais minerais encontrados em frutas, legumes e hortaliças é bastante esporádica. Não há costume de cultivar hortas nos quintais, geralmente as crianças alimentam-se de frutas nos períodos de safra, como a manga, caju, cupuaçu e pupunha, as mais encontradas em diferentes períodos do ano.

"Eles gostam demais de fruta, toda fruta que têm quando ta na época eles comem muito, mas de comida mesmo é o peixe que o pai deles pesca, comer galinha é difícil, feijão também, a gente come pouco, ainda mais agora que feijão ta muito caro, é mais peixe mesmo." (Marai).

No cuidar-educando o enfermeiro precisa levar em conta que os nutrientes que qualquer grupo humano se alimenta estão arraigados de inúmeros significados biológicos e simbólicos, nos quais os indivíduos assumem para si como verdades. Há 
um papel central do alimento na vida cotidiana, especialmente nas relações sociais; as crenças e as práticas relacionadas à dieta são notoriamente difíceis de serem mudadas, mesmo quando interferem com a nutrição adequada(17).

Estudos sobre desnutrição alertam para os fatores desencadeantes, e indicam que o cuidado com a alimentação no contexto doméstico-familiar (tabus alimentares, acesso restrito à nutrientes essenciais, dentro outros aspectos), é um dos determinantes da saúde da criança de 0 a 5 anos.

$\mathrm{Na}$ Cartilha reforçamos o uso das frutas locais, destacamos receitas para os períodos de safra; reforçamos vantagens das hortas caseiras; ilustramos essa parte com a pirâmide alimentar para realçar a importância do equilíbrio na distribuição dos nutrientes da dieta da criança.

Todos os participantes falaram sobre a relevância de cuidar pela amamentação, e que seus filhos de 0 a 5 anos foram amamentados ao seio materno exclusivo, pelo menos até os seis meses de idade.

"Eu dei de mamar pro meu filho até um ano, a partir dos seis meses eu comecei a dar aquelas sopinhas de pacote pra ele. Pra mim amamentar o meu filho foi importante, porque assim ele fica mais saudável, ele não queria sair do peito." (Maguari).

"É muito importante pra mim, né, principalmente quando nasce dente que não quer comer, aí tem que dar mama." (Jauarituba).

"Elas mamam geralmente até um ano, minha pequena ainda mama, é bom pra elas mamarem pra ficar com saúde, engordar." (Takuara).

Para reforçar esse aspecto, na Cartilha relacionamos a amamentação ao estabelecimento e fortalecimento dos laços e vínculos mãe-filho.

Foi possível notar que as famílias sabem da importância do cuidado com a vacinação e dão o devido valor para a prática no intuito de prevenir e combater as doenças comuns nessa faixa etária. Para enfrentar a dificuldade de manter em dia o esquema vacinal, devido à distância da cidade, utilizam as visitas à comunidade do barco Abaré para poder manter as vacinas em dia e assim evitar que seus filhos adoeçam. A vacinação deve constituir uma das principais preocupações do cuidar-educando da saúde da criança(18). Sobre esse aspecto, colocamos na Cartilha o esquema vacinal completo, pois cabe aos profissionais zelar pela resolutividade e repasse de informações relacionadas a este cuidado. Também destacamos que algumas crenças sobre contraindicações para a vacinação não tem fundamento e podem prejudicar a atualização do esquema.

No cuidar-educando em contextos ribeirinhos, tem-se que levar em conta também que o uso de práticas alternativas na perspectiva do cuidado popular são comuns, principalmente pela dificuldade de acesso aos serviços formais de saúde. $O$ uso de remédios caseiros é muito valorizado pelos informantes, que relatam utilizá-los com freqüência principalmente para moléstias comuns da infância, como a gripe, por exemplo
"Eu faço uso de remédio caseiro, casca de manga, cumaru, mistura com açúcar e é bom pra gripe e pra tosse, chá de alho também é bom." (Açaituba)

"Quando elas ficam doentes eu faço remédio, mas só quando é leve, dou mel de abelha pra gripe, chá de casca de laranja pra dor de barriga." (Takuara)

"Eu acredito mais em remédio caseiro que no de farmácia, sempre eu faço remédio e fica bom, não sei se é minha fé que faz curar." (Maraí)

Os remédios caseiros utilizados na comunidade traduzem a realidade local e é uma forma de solucionar problemas simples. A população quando doente recorre a várias técnicas de cura, representando formas alternativas de curar(17). Pudemos notar que os remédios relatados pelos informantes não são utilizados exclusivamente em comunidades ribeirinhas, pois muitos de nós já tomamos algumas dessas misturas quando éramos crianças.

$\mathrm{Na}$ Cartilha procuramos relacionar algumas receitas com plantas identificadas na comunidade; destacamos os princípios ativos, doses recomendadas e modos de preparo e conservação. Um dos problemas entre as famílias é que fazem o chá e ficam tomando todo o dia, o que não é indicado, pois o princípio ativo não permanece com o mesmo efeito. Uma das informantes, após essa explicação referiu.

"Depois dessa explicação vou dizer pras minhas filhas que chá não é água." (Açaituba).

O acesso aos serviços de saúde, em comunidades ribeirinhas principalmente, têm que ser considerado, e neste estudo, a distância que separa Tauari dos municípios de Santarém e Belterra é um fator sempre apontado pelos moradores da comunidade como problemático em relação à saúde das crianças. E esse problema se agrava quando ocorre alguma alteração que faz com que as crianças fiquem doentes, porque só há um ônibus que faz linha da comunidade para Santarém e só opera três vezes por semana e ainda nem sempre as famílias têm dinheiro para pagar a passagem.

"Nós somos esquecidos aqui na comunidade, e se um filho da gente tiver de morrer, morre mesmo aqui, e não dá de fazer nada. Esse negócio de transporte é ruim, porque nem sempre a gente tem dinheiro pra pagar a passagem. E quando vai pra Belterra, o ônibus só deixa no portão. De lá pra dentro se não tiver dinheiro pra pagar aqueles mototáxistas, fica lá no solzão quente até vir o ônibus que vem de Santarém pra entrar. (...) e quando chega lá ainda tem de esperar ficha, esperar vez, remarcar e assim é complicado, complicado demais" (Acaratinga); "Quando fica doente eu tento resolver por aqui, se a doença é mais grave e ruim, porque não tem carro pra levar pra cidade e é muito distante" (Piní).

É preciso prestar assistência primária à população tornando-a sujeito de suas próprias ações de saúde(18). Por acreditarmos 
nessa assertiva e em ações inclusivas e participativas, levamos em consideração os discursos na elaboração da tecnologia educativa intitulada "Criança Saudável", organizada em torno das unidades temáticas identificadas na Fase 1, e submetida a validação na Fase 2. Tomamos como referência os (dês) conhecimentos, desafios, limites, dúvidas e afirmações feitas pelas famílias no trato da saúde da criança de 0 a 5 anos.

\section{VALIDAÇÃO DE UMA TECNOLOGIA EDUCATIVA PARA FAMÍLIAS RIBEIRINHAS}

As sugestões e comentários para o material educativo, indicadas por juízes e público-alvo foram: adicionar mais receitas de remédios caseiros; incluir nas doenças a leishmaniose e sua prevenção; mudar a fonte para facilitar a leitura; acrescentar à composição do leite materno a água; mudar a posição da parte que fala sobre cultura; acrescentar que o aleitamento materno pode se estender até os 2 anos ou mais como um complemento alimentar; colocar na p.6 que na próxima mamada deve-se oferecer a outra mama; descrever alimentos que ajudam o dente a ficar saudável; transferência do texto “Tratamento da água para a página da diarréia; substituição de alimentos nas receitas das papinhas (aveia, iogurte, farinha láctea), por outros alimentos existentes na comunidade; fazer modificações no calendário de vacinação; alertar sobre os perigos de acidentes na infância inerentes ao processo de desenvolvimento infantil; propor alternativas de brincadeiras ou atividades lúdicas que possam ser desenvolvidas pelas famílias junto com as crianças, levando em consideração os meses de cheia do rio onde a criança fica sem local para brincar.

Todas as sugestões foram acatadas, tendo em vista que os juízes-especialistas além da visão técnica de área evidenciaram um olhar antropo-eco-social, o que se fez notar em muitas das sugestões relacionadas ao saber local, a natureza e a cultura.

Quanto à avaliação de conteúdo, destacamos que as respostas dos juízes nos três blocos de itens avaliados foram: 55 $(50 \%)$ para totalmente adequado (TA), 32 (30\%) para adequado (A), $23(20 \%)$ para parcialmente adequado (PA), $0(0 \%)$ para inadequado (I). Houve uma tendência dos juízes a optarem pelas respostas de forma concordante. A maioria das respostas ficou entre TA (55); A (32) e PA (23). Diante disso, pode-se inferir que não houve indicação significativa de discordância. Vejamos a avaliação em cada Bloco.

Bloco 1 (objetivos): avalia os propósitos, metas ou fins a serem atingidos com a utilização do manual. As respostas dos juízes foram: $15(60 \%)$ para TA, 7 (28\%) para A, 3(12\%) para PA. Sobre esse aspecto o material educativo é adequado quanto aos objetivos propostos.

Bloco 2 (estrutura e apresentação): avalia a forma de apresentar as orientações. Isto inclui sua organização geral, sua estrutura, estratégia de apresentação, coerência e formatação. As respostas dos juízes foram: 28 (47\%) para TA, 17 (28\%) para A, $15(25 \%)$ para PA. Sobre esse aspecto o material educativo é adequado quanto à estrutura e apresentação.

Bloco 3 (relevância): avalia o grau de significação do material educativo. As respostas dos juízes foram: 12 (48\%) para TA, $8(32 \%)$ para A, $5(20 \%)$ para PA. Sobre esse aspecto o material educativo é adequado quanto a relevância.

A análise da representação comportamental dos itens é o nome dado para o valor da estatística calculada que corresponde à média aritmética dos escores do item analisado pelos juízes (1 é usado quando a avaliação é positiva, ou seja, TA ou A; 0 quando não é nem positiva nem negativa, ou seja, PA; e -1 quando a avaliação é negativa, ou seja, I). Foram considerados validados os itens que obtiveram nas respostas índices de concordância entre os juízes maior ou igual a 70\%, como apontado pela literatura ${ }^{(13)}$. No Bloco 1, os 5 itens foram validados; no Bloco 2, dos 12 itens, 2 não foram validados (2.3: as informações apresentadas estão cientificamente corretas; 2.9: o tamanho do titulo e dos tópicos estão adequados); no Bloco 3 os 5 itens foram validados.

Quanto à avaliação semântica, as respostas do público-alvo em todos os Blocos foram: 212 (65.2\%) para TA, 111 (34.1\%) para A, $2(0.6 \%)$ para PA. Houve uma tendência do público-alvo a optar pelas respostas de forma concordante. A maioria das respostas ficou entre TA (212); A (111); PA (2). Diante disso, reitera-se que não houve indicação significativa de discordância.

\section{CONSIDERAÇÕES FINAIS}

Conhecer os saberes e modos de cuidar das famílias ribeirinhas, relacionados à saúde da criança de 0 a 5 anos, nos fez concluir, com base na complexidade revelada, que os profissionais de saúde, e em especial as(os) enfermeiras(os) precisam fazer aproximações sucessivas das comunidades onde atuam, pois o que identificamos na comunidade do Tauari representa o cuidado cultural local, diretamente imbricado com crenças, tradições, possibilidades e geo-espacialidades características daquela comunidade. Não há um cuidado genérico. O que precisamos compreender e fazer é a escuta sensível de cada realidade. Essa foi nossa primeira lição. Não dá para chegar "lá", seja onde for, com receitas prontas e prescrições de cuidado elaboradas. É preciso chegar, se acomodar, aprender a observar, ouvir, trocar, antes de qualquer ação-intervenção cuidativa-educativa.

As formas de cuidar das famílias para com a criança de 0 a 5 anos revelam-se marcadas tanto pela diversidade de saberes como pelas adversidades do viver ribeirinho; os saberes que estão envolvidos no cuidar da criança de 0 a 5 anos são os mesmos que as demais crianças demandam, mas as estratégias cuidativas operacionalizadas e os saberes a elas articulados dependem das transferências intergeracionais, dos fatores socioeconômicos, ambientais, religiosos e culturais das tradições herdadas ao longo das gerações, que se manifestam na forma de cuidar das famílias, o que indica um cotidiano atravessado não só pelos rios, mas também por densas travessias de saberes locais-populares.

No que tange a validação da tecnologia educacional, os aspectos destacados por juízes-especialistas e público-alvo sobre a tecnologia educativa elaborada com base nos limites e potencialidades dos saberes revelados, apontaram que as inserções locais, as considerações culturais e as negociações societais são fatores imprescindíveis na preparação-produção de materiais educativos.

A oportunidade de criar um manual educativo fez-nos perceber o quanto os profissionais de enfermagem precisam ser 
criativos e persistentes, na busca pela melhoria de vida das pessoas. Ao nos depararmos com a realidade das famílias ribeirinhas, observamos presença e ausência de informações sobre o cuidado com as crianças de 0 a 5 anos. Portanto, a criação de materiais como este, pode ajudar as famílias no cuidado de suas crianças, promovendo assim uma vida mais saudável, por meio do acesso à informação. A validação do manual indica-nos que é preciso acreditar na promoção da saúde entre as famílias ribeirinhas, bem como instigar outros estudantes e profissionais da área de saúde na construção de outros materiais didáticos, ampliando assim o número de tecnologias educativas em saúde.

Retratar a cultura e os modos de cuidar das famílias ribeirinhas da comunidade de Tauari foi de certa forma resgatar a história das demais localidades que assim como esta, surgiram e se fixaram às margens dos rios no meio da floresta amazônica. Esta pesquisa revelou de forma singular o modo de viver dessas comunidades amazônicas, fundadas por diversos grupos, entre eles, o caboclo amazônico, que surgiu do processo de ocupação da Amazônia, localizando-se às margens dos rios fundando comunidades ribeirinhas, tornando-se, assim, típico da região.

O que existe em comum na história destas comunidades é o desejo de liberdade e busca pela sobrevivência, razão pela qual surgiram, incumbindo estes indivíduos a uma luta diária contra as condições que o meio lhes condiciona, o clima, o solo a densidade, os riscos da floresta, a força das águas, as patologias prevalentes, perpassando ainda os problemas atuais, como a dificuldade de transporte, assistência à saúde, questões de terra, falta de incentivos ao desenvolvimento econômico local, que transformaram estas pessoas comuns em homens de fé e luta, em criadores de lendas, mitos, poções, usados como artifícios na arte da cura e manancial de força em uma jornada de equilíbrio com o poder da natureza; assim, conquistaram seu espaço e desenharam sua história, fazendo da fauna e flora sua fonte de alimento para o corpo e a alma.

A oportunidade que a iniciação científica nos deu para compreender como são as práticas de cuidar das famílias ribeirinhas é e será o fio condutor para o nosso cuidar-educando na enfermagem; hoje cremos que entender como está a saúde das crianças, exige que nos envolvemos com questões sócio-políticas e econômicas que estão entrelaçadas aos condicionantes de saúde-doença bem como às culturas locais, que necessitam ser contadas, observadas e compreendidas.

Novos estudos devem surgir, pois os costumes diários atravessam gerações, e são lapidados no dia-dia; dos hábitos de higiene às intervenções mais complexas em casos de processos patológicos, os sujeitos cuidadores travam uma luta incansável contra as condições adversas a fim de manter a saúde e o bem estar de seus filhos. Nós só precisamos estar atentos para isso.

\section{REFERÊNCIAS}

1. Carvalho D. Cuidar e Prevenir: os saberes familiares tradicionais e medicinais acerca da saúde e da doença. Anais V Congresso Português de Sociologia. Sociedades Contemporâneas, 2006. Disponível em: http://www.aps.pt/ cms/docs-pw/dpr4628f6505c95-1pdf.

2. Teixeira E. Travessias, redes e nós: complexidade do cuidar cotidiano da saúde entre ribeirinhos. Belém (PA): Grafisa; 2002.

3. CNBB. Clipping Eletrônico Pastoral da Criança. Disponível em: http://esquel.org.br/imprensa/clipping/200504/ pastoral da crianca 08042005.doc.

4. Brasil (MS). Acompanhamento do crescimento e desenvolvimento infantil. Série Cadernos de Atenção Básica. Brasília (DF); 2002.

5. Oliveira VC. A consulta de enfermagem no acompanhamento do crescimento e desenvolvimento infantil. Rev. Min. Enferm. 2007; 11(1):77-80.

6. Regiani C, Correa I. Acidentes na infância em ambiente domiciliar. Rev. Min. Enferm. 2006; 10(3): 277-9.

7. Frota MA, Albuquerque CM, Linard AG. Educação popular em saúde no cuidado à criança desnutrida. Texto Contexto Enferm. 2007 abr/jun; 16(2): 246-53.

8. Cabral IE, Aguiar, RCB. As políticas públicas de atenção à saúde da criança menor de cinco anos: um estudo bibliográfico. Rev. Enferm. UERJ. 2003 set/dez; 11(3): 285-291.

9. Kawamoto EE. Enfermagem Comunitária. São Paulo (SP): EPU; 1995
10. Remor CB, Pedro VL, Ojeda BS, Gerhardt LM. Percepções e conhecimentos das mães em relação às práticas de higiene de seus filhos. Esc Anna Nery Rev Enferm. 2009 out-dez; 13 (4): 786-92.

11. Araújo YB, Collet N, Moura FM, Nóbrega RD. Conhecimento da família acerca da condição crônica na infância. Texto Contexto Enferm. 2009 jul/set; 18 (3): 231-42.

12. Hoffmann, MV, Oliveira ICS. Conhecimento da família acerca das crianças de 1 a 5 anos em uma comunidade ribeirinha: subsídios para a enfermagem brasileira. Esc. Anna Nery Rev. Enferm. 2009 dez;13(4):750-756.

13. Polit DF, Beck CT, Hungler BP. Fundamentos de pesquisa em enfermagem: métodos, avaliação e utilização. $5^{a}$ ed. Porto Alegre (RS): Artmed; 2004.

14. Morin E. Introdução ao pensamento complexo. Lisboa; Porto Editora; 2008.

15. Poleti $L N$ et.al. Recreação para crianças em sala de espera de um ambulatório infantil. Rev Bras Enf. 2006 mar/abr; 59 (1): $23-9$

16. Macedo JAB, Barra MM. Derivados clorados de origem orgânica: uma solução para o processo de desinfecção de laticínios e de água potável. Hig. aliment. 2002 jul; 16(98): 29-37.

17. Helman CG. Cultura, saúde e doença. Porto Alegre (RS): Artmed; 2003.

18. Mello DF, Ferriani MG. Estudo Exploratório de opiniões de mães sobre a saúde das crianças menores de 5 anos. Rev. Latino-Am. Enfermagem. 2006; 4 (2): 122-3 